\title{
Andre Antunes
}

Title of presentation:

Extreme Red Sea: Life in the Deep-Sea Anoxic Brine Lakes

\section{Abstract:}

Tectonic splitting of the Arabian and African plates originated the Red Sea together with one of the most unique, remote, and extreme environments on Earth: deep-sea anoxic brine lakes. They combine multiple extremes namely increased salinity (7-fold), temperature (up to $70^{\circ} \mathrm{C}$ ), concentration of heavy metals (1,000- to 10,000 -fold), and hydrostatic pressure [1].

Despite such harsh conditions, they harbor an unexpectedly high biodiversity and are teeming with life. Increased interest in their microbiology led to multiple recent and ongoing studies. Highlights of this research include: the isolation, physiological characterization and genome sequencing of unusual new extremophilic microbes; the identification of several novel phylogenetic lineages; and ongoing cultivation- and molecularbased assessment of microbial community variation between and within different brines [2-7].

The uniqueness of these environments offers a high potential for discovery of new microbes, strategies and biomolecules to cope with extreme conditions, and biotechnological applications.

\section{References}

1. Antunes, et al. (2011). Microbiology of the Red Sea (and other) deep-sea anoxic brine lakes. Environ Microbiol Rep, doi:10.1111/j.1758-2229.2011.00264.x

2. Antunes, et al. (2003). Salinisphaera shabanensis gen. nov., sp. nov., a novel, moderately halophilic bacterium from the brine-seawater interface of the Shaban Deep, Red Sea. Extremophiles, 7, 29-34. doi:10.1007/s00792-002-0292-5

3. Antunes, et al. (2008). Halorhabdus tiamatea sp. nov., a non-pigmented, extremely halophilic archaeon from a deep-sea, hypersaline anoxic basin of the Red Sea, and emended description of the genus Halorhabdus. Int J Syst Evol Microbiol, 58, 215-220. doi:10.1099/ijs.0.65316-0

4. Antunes, et al.(2008).A new lineage of halophilic, wall-less, contractile bacteria from a brine-filled deep of the Red Sea. J Bacteriol, 190, 3580-3587. doi:10.1128/JB.0186007 
5. Antunes, et al. (2011). Genome sequence of Halorhabdus tiamatea, the first archaeon isolated from a deep-sea anoxic brine lake. J Bacteriol, 193, 4553-4554. doi:10.1128/ JB.05462-11

6. Antunes, et al. (2011). Genome sequence of Salinisphaera shabanensis, a gammaproteobacterium from the harsh, variable environment of the brine-seawater interface of the Shaban Deep in the Red Sea. J Bacteriol, 193, 4555-4556. doi:10.1128/ JB.05459-11

7. Antunes, et al. (2011). Genome sequence of Haloplasma contractile, an unusual contractile bacterium from a deep-sea anoxic brine lake. J Bacteriol, 193, 4551-4552. doi:10.1128/JB.05461-11

Short biography:

André Antunes is an environmental microbiology researcher at the University of Minho (Portugal), having devoted most of his research life to the study of microbial communities thriving at the environmental extremes present in the deep-sea anoxic brine lakes of the Red Sea.

He studied Biology and received his PhD in Biochemistry at the University of Coimbra (Portugal). His PhD research focused on the deep-sea brines of the Red Sea and was developed at the prestigious Lehrstuhl fur Mikrobiologie und Archaeenzentrum, University of Regensburg (Germany), and continued his research as post-doc at the University of Coimbra (Portugal).

In 2007 he joined the University Jean Piaget (Cape Verde) as an Assistant Professor, but in 2009 embraced the return to his research topic after joining the Red Sea Research Center at King Abdullah University of Science and Technology (Saudi Arabia) as a postdoctoral fellow. During this period, his research received considerable attention and has received significant funding from external sources.

In late 2012 he joined the Centre of Biological Engineering at the University of Minho (Portugal), as a post-doctoral fellow. He is one of the national key-representatives associated with the European Union's 7th Framework Programme funded "MIRRI - Microbial Resource Research Infrastructure" project.

His main research interests focus on the environmental microbiology of marine and extreme environments in the Red Sea and elsewhere. He is particularly interested in microbial biodiversity and adaptations to extreme conditions.

\section{The 6th}

